Part of Journal of Research of the National Bureau of Standards, Volume 14, June 1935

\title{
EFFECT OF ANTIOXIDANTS ON THE NATURAL AND THE ACCELERATED AGING OF RUBBER
}

\author{
By Rees F. Tener and William L. Holt
}

\section{ABSTRACT}

Five different rubber compounds, in each of which were incorporated different antioxidants, were subjected to the following five conditions: (1) Dark storage, (2). weather exposure, (3) air at $70^{\circ} \mathrm{C}$, (4) air at $90^{\circ} \mathrm{C}$, and (5) oxygen at 300 pounds pressure per square inch at $60^{\circ} \mathrm{C}$. Tensile-strength tests were made on these compounds at suitable intervals. The periods of exposure ranged from a few days in the case of high-temperature tests to seven or eight years under conditions of dark storage. The results are shown in graphs which consist of 10 sets of tensile-strength-time curves. Two means are suggested for expressing the effectiveness of antioxidants numerically - a time index, which is a measure of the increase in time during which a rubber compound will remain serviceable, and a tensile index, which is a measure of the improvement in average tensile strength when compared with samples containing no added antioxidant. The effectiveness of antioxidants varied between wide limits, depending upon the type of compound, the particular antioxidant used, and the conditions of exposure. A comparison of the indexes obtained by different accelerated tests with those obtained under some conditions of natural aging affords a means for choosing an aging test best suited to a particular rubber product.

\section{CONTENTS}

I. Introduction

II. Antioxidants and rubber compounds employed

III. Conditions of test

IV. Interpretation of results.

1. Tensile index

2. Time index

3. Computation of tensile and time indexes

4. General effect of antioxidants_.._. 680

5. Behavior of antioxidants in different compounds $\ldots$

6. Behavior of antioxidants under different conditions of expo- 681

7. Relative value of antioxidants

V. Summary

\section{INTRODUCTION}

This paper describes a study of the effect of several commercial antioxidants on the deterioration of typical, soft rubber compounds when exposed to the weather, stored in a dark cabinet at room temperature, and subjected to accelerated aging in air, and in compressed oxygen at elevated temperatures. The tensile strength of the rubber at break is taken as a measure of the deterioration. The results have been interpreted in terms of the improvement in tensile strength and the increase in the useful life of the rubber afforded by the antioxidant. The value of a given antioxidant is found to vary with the compound in which it is used and with the conditions of test. Under some cir- 
cumstances the antioxidant has little effect on the rubber, but under other conditions it may increase the tensile strength and lengthen the life of rubber to a marked extent. Broad comparisons between antioxidants are not possible because the manner in which each antioxidant functions depends on specific conditions and no single material appears the best under all circumstances. The word antioxidant is understood, in the practical sense, to mean a substance that is added. to rubber to increase its useful life.

Natural rubber contains certain substances which, though present in very small amount, afford a high degree of protection against oxidation. Indeed, when these natural antioxidants are removed the useful life of rubber is a matter of only a few days. Methods have been devised for separating these materials from crude rubber, but their chemical identification is not yet definite or complete. ${ }^{1}$

The antioxidants which are the subject of this investigation are synthetic organic materials that are unrelated to the natural antioxidants in chemical structure. They also are less effective than the natural antioxidants, since they are used in amounts of the order of 1 percent, while the natural antioxidants in crude rubber do not exceed 0.1 percent of the total.

In studying the behavior of synthetic antioxidants, rubber which contains the natural antioxidants was compared with the same rubber to which a synthetic antioxidant had been added.

A complicating factor in the investigation is the fact that the substances investigated have other than purely antioxidant functions. Some of them are also accelerators of vulcanization, and consequently affect the optimum time of vulcanization and change the physical properties of a vulcanized compound. Conversely, some of the accelerators used in the rubber compounds served not merely to speed up the vulcanization reaction, but had distinct antioxidant activity as well. In order to evaluate these dual functions, antioxidants having varying acceleration activity and accelerators having varying antioxidant power were selected.

References to previous investigations may be found in a recent comprehensive review on the subject of the accelerated aging of soft, vulcanized rubber. ${ }^{2}$ The contribution of the present paper consists of data pertaining not only to accelerated-aging tests, but also to natural life tests extending over as much as eight years. These data are interpreted so as to yield numerical factors expressing the improvement in tensile strength and the increase in the useful life of rubber which result from the employment of antioxidants under specified circumstances.

\section{ANTIOXIDANTS AND RUBBER COMPOUNDS EMPLOYED}

The antioxidants used in this investigation were selected from commercial antioxidants that were available when the work was begun. They were purchased under trade names, but are here designated by their chemical names. The identification was based on statements by the manufacturers or on information from other sources believed to be reliable.

1 H. A. Bruson, L. B. Sebrell, and W. W. Vogt, Isolation of the natural oxidation inhibitors of crude Hevea rubber. Ind. Eng. Chem. 19, 1187-1191 (1927).

${ }_{2}$ T. R. Dawson, The Research Association of British Rubber Manufacturers, Information Bureau J. 3, 51-96 (May, June, July, and August 1934). 
No analyses were made of the antioxidants nor was their purification undertaken since the aim was to study the performance of the commercial materials when used in accordance with instructions furnished by the manufacturer.

A list of the antioxidants employed is given in table 1, together with information about their form, and the color which they impart to rubber. Inasmuch as the chemical names of the antioxidants are cumbersome, letters are given in this table, which will be used to refer to the antioxidants in the subsequent discussion.

TABLE 1.-Antioxidants employed

\begin{tabular}{|c|c|c|}
\hline $\begin{array}{l}\text { Designa- } \\
\text { nation }\end{array}$ & Antioxidant & $\begin{array}{l}\text { Effect on light-colored } \\
\text { rubber }\end{array}$ \\
\hline A. & Aldol-alpha-naphthylamine. & Slight coloring. \\
\hline & Acetaldehyde-aniline reaction product..... & Distinct coloring. \\
\hline & 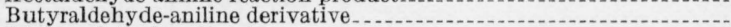 & Decided darkening. \\
\hline D... & Diphenylethylenediamine & Slight coloring. \\
\hline E... & $\begin{array}{l}\text { Mixture of phenyl-alpha-naphthylamine, meta-toluylenediamine, and } \\
\text { stearic acid. }\end{array}$ & Decided darkening. \\
\hline
\end{tabular}

Five rubber compounds were used. These were compounded at the Bureau, and were formulated with a view to representing widely different types of rubber compounds, and comprised the following: a simple rubber-sulphur mixing, a pure gum compound made with an ultra-accelerator, a whiting stock, a carbon-black tread stock, and a compound containing carbon black and reclaimed rubber. The accelerators were selected to show a range of antioxidant activity and included diorthotolylguanidine and diphenylguanidine, which are regarded as having no antioxidant activity, hexamethylenetetramine, which has moderate activity, and tetramethylthiuram disulphide, which markedly improves the stability of rubber. The formulas for the respective compounds are shown in table 2, while in table 3 the amounts of the various antioxidants used in each are given. As indicated previously, the latter proportions are based on recommendations made by the manufacturers at the time this work was undertaken.

The periods of vulcanization of the various compounds are shown in table 4.

TABLE 2.-Composition of base rubber compounds (in parts by weight)

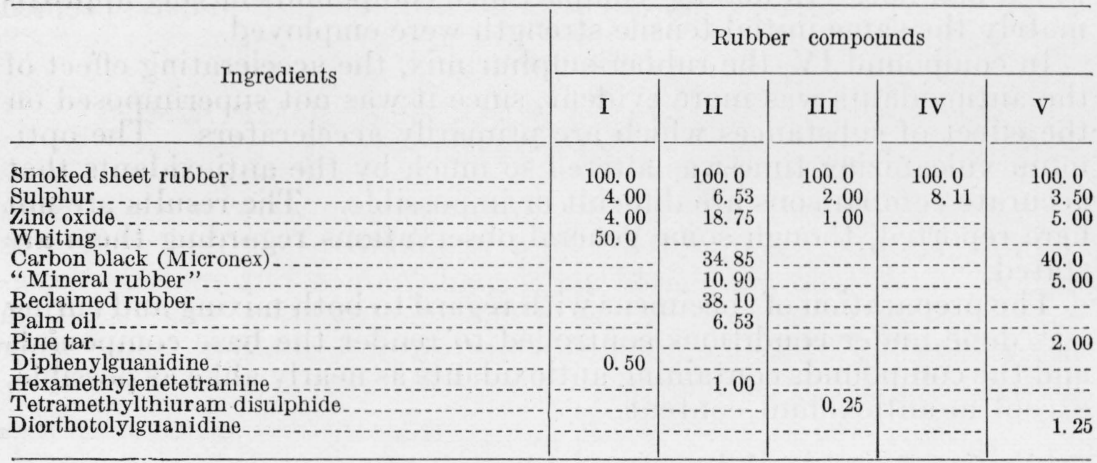


TABLE 3.-Amounts of antioxidants added, in percentage by weight of the rubber in the base rubber compound

\begin{tabular}{|c|c|c|c|c|c|}
\hline \multirow{2}{*}{ Antioxidant } & \multicolumn{5}{|c|}{ Rubber compounds } \\
\hline & I & II $^{1}$ & III & IV & $\mathrm{v}$ \\
\hline $\begin{array}{l}\text { A } \\
\text { B } \\
\text { C } \\
\text { D } \\
\end{array}$ & $\begin{array}{l}1.0 \\
2.5 \\
1.5 \\
2.5 \\
2.5\end{array}$ & $\begin{array}{r}1.0 \\
2.5 \\
1.5 \\
\text { None } \\
\text { None }\end{array}$ & $\begin{array}{l}1.0 \\
2.5 \\
1.5 \\
2.5 \\
2.5\end{array}$ & $\begin{array}{r}1.0 \\
2.5 \\
1.5 \\
\text { None } \\
\text { None }\end{array}$ & $\begin{array}{r}\text { None } \\
\text { None } \\
\text { None } \\
2.5 \\
2.5\end{array}$ \\
\hline
\end{tabular}

${ }_{1}$ Reclaimed rubber was calculated as 50 percent rubber.

TABLE 4.-Conditions under which samples were vulcanized

\begin{tabular}{|c|c|c|c|}
\hline Rubber compounds & $\begin{array}{l}\text { Antioxidants } \\
\text { employed }\end{array}$ & $\begin{array}{l}\text { Tempera- } \\
\text { ture of vul- } \\
\text { canization }\end{array}$ & $\begin{array}{l}\text { Periods of vul- } \\
\text { canization }\end{array}$ \\
\hline $\begin{array}{l}\text { I } \\
\text { II } \\
\text { III } \\
\text { III } \\
\text { IV } \\
\text { V }\end{array}$ & $\begin{array}{r}\text { A, B, C, } \mathbf{D}, \mathbf{~} \\
\text { A, } \\
\text { A, } \\
\text { B, } \\
\text { D, } \\
\text { A, B, } \\
\text { D, } \\
\text { E }\end{array}$ & $\begin{array}{r}\text { Degrees } \mathrm{C} \\
142 \\
145 \\
125 \\
125 \\
142 \\
142\end{array}$ & $\begin{array}{l}\text { Minutes } \\
20,30 \text {, and } 50 \\
25,50 \text {, and } 90 \\
23 \\
18,23 \text {, and } 28 \\
\text { (a) } \\
30,37 \text {, and } 45\end{array}$ \\
\hline
\end{tabular}

a Several different periods were employed.

When this work was initiated, the removal of from 5 to 15 percent of the accelerator from a batch was suggested in order to compensate for the accelerating action of certain antioxidants. Additional mixes of compounds I and II, in which diphenylguanidine and hexamethylenetetramine were employed as accelerators, were made up with the elimination of a portion of the accelerators according to this recommendation. The results, however, did not differ materially from those obtained when the full amount of accelerator was used. With compound III, on the other hand, the addition of some of the antioxidants had the effect of producing considerably higher initial tensile strengths so that a comparison between a compound with and without an antioxidant was difficult. By deducting a portion of the accelerator, compounds of approximately the same initial tensile strength were obtained with and without antioxidants. Aging tests were made on compounds which had been altered in this way and on those which had not. In making comparisons, compounds having approximately the same initial tensile strength were employed.

In compound IV, the rubber-sulphur mix, the accelerating effect of the antioxidants was more evident, since it was not superimposed on the effect of substances which are primarily accelerators. The optimum vulcanizing time was altered so much by the antioxidants that accurate comparisons are difficult or impossible. The results are not here reported, though some general observations regarding them are stated.

The preparation of specimens with regard to both mixing and curing was done under conditions controlled to render the base compounds and the compounds containing antioxidants as nearly alike as possible, except in antioxidant content. 


\section{CONDITIONS OF TEST}

The test conditions were chosen so as to study the deterioration of rubber exposed to a variety of circumstances, including those of the familiar accelerated-aging tests. They comprised exposure to:

(1) Air at prevailing room temperature in a dark cabinet, (2) sunlight and weather, (3) air at $70^{\circ} \mathrm{C}$, (4) air at $90^{\circ} \mathrm{C}$., and (5) oxygen under pressure of 300 pounds per square inch at $60^{\circ} \mathrm{C}$.

The dark-storage tests were made by suspending the samples in a cabinet located in a well-ventilated room. The sides of the cabinet consisted of black cloth, which permitted the circulation of air, but excluded practically all of the light.

The weather-exposure tests were conducted by hanging sheets of the various experimental compounds on racks that were placed on the the roof of a building of the Bureau, which is situated in a suburban area. The sheets were suspended vertically in an east and west plane so that only one side was exposed to direct sunlight during most of the year.

The tests in air at 70 and $90^{\circ} \mathrm{C}$ were conducted in an electric oven in which the air was stirred by means of a fan mounted at the bottom. The introduction of fresh air into the oven was secured by convection through open ventilators.

The compressed-oxygen test differed from the test commonly required in specifications for rubber articles in that a temperature of $60^{\circ} \mathrm{C}$ was employed instead of $70^{\circ} \mathrm{C}$. The bomb in which the test was conducted was made from an iron pipe about 8 inches in diameter and 12 inches in length, and was mounted in a thermostatically controlled water bath. No detailed record was kept of the number and kinds of samples that were placed in the bomb together. The volume of rubber introduced into the bomb at any one time did not exceed 3 percent of the volume of the bomb. When tests were being made at different time intervals, all the samples required were placed in the bomb at one time, and some were withdrawn at intervals until the longest aging period was reached. The samples used for the bomb test were 3 - by 5 -inch strips from which dumbbell-shaped test specimens were subsequently cut.

The accelerated-aging tests were completed in six weeks or less. The sunlight- and weather-exposure test in some cases extended over eighteen months. In dark storage most of the samples deteriorated slowly, and after seven or eight years several lots of them had practically their original tensile strength. The duration of the tests was sufficiently long in most cases to permit comparisons between different types of aging and to give data on the effectiveness of antioxidants.

\section{INTERPRETATION OF RESULTS}

In order to simplify the presentation of results, measurements have been averaged wherever practicable. In some instances the measurements for different cures are averaged. In others, only the measurements at optimum cure are given. In condensing the bulk of data, care has been exercised not to average measurements in a way that might obscure trends or affect the conclusions. For compound II, the results are expressed as the averages of the measurements at the two shorter periods of vulcanization in one group and those at the longest period in another. 
The results are presented graphically in figures 1 to 10 . Each figure refers to one condition of aging and consists of two groups of curves representing two different compounds. The ordinates represent the tensile strength and the abscissas the time of aging.

The mass of data presented is too great to admit of simple or easy interpretation by the usual method of making a visual inspection of

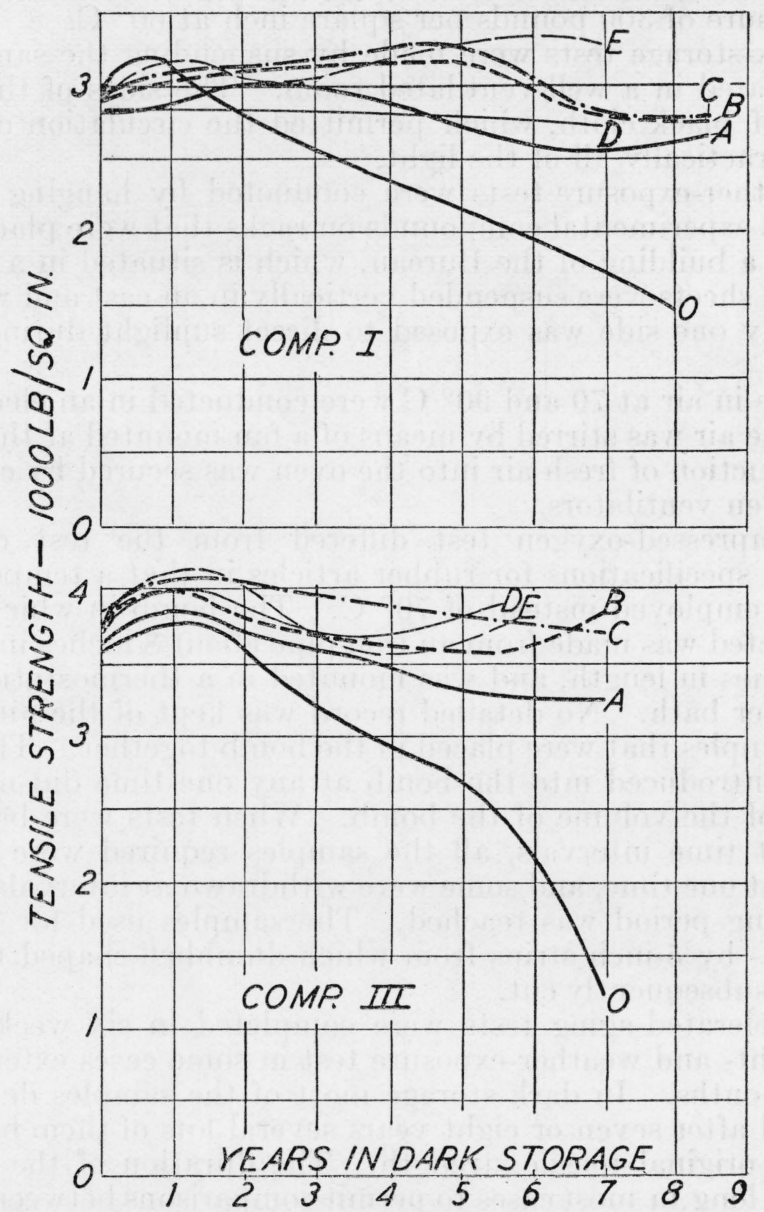

FIGURE 1.-Tensile-strength-time curves for compounds I and III under dark-storage conditions.

Letter 0 indicates base compound (no antioxidant). A, B, C, etc., refer to antioxidants listed in table 1.

the curves. This difficulty is accentuated by the fact that the curves are irregular and do not conform closely to any simple or well-defined shape. For this reason quantitative means of evaluating the effect of antioxidants were devised on the basis of comparisons of certain areas under the aging curves of compounds made with and without antioxidants, respectively. The improvement in tensile strength is called the tensile index, and the increase in the useful life is called the time 
index. These indexes are intended simply as practical expedients. They are not precisely determinable numbers, nor do they have any fundamental physical significance.

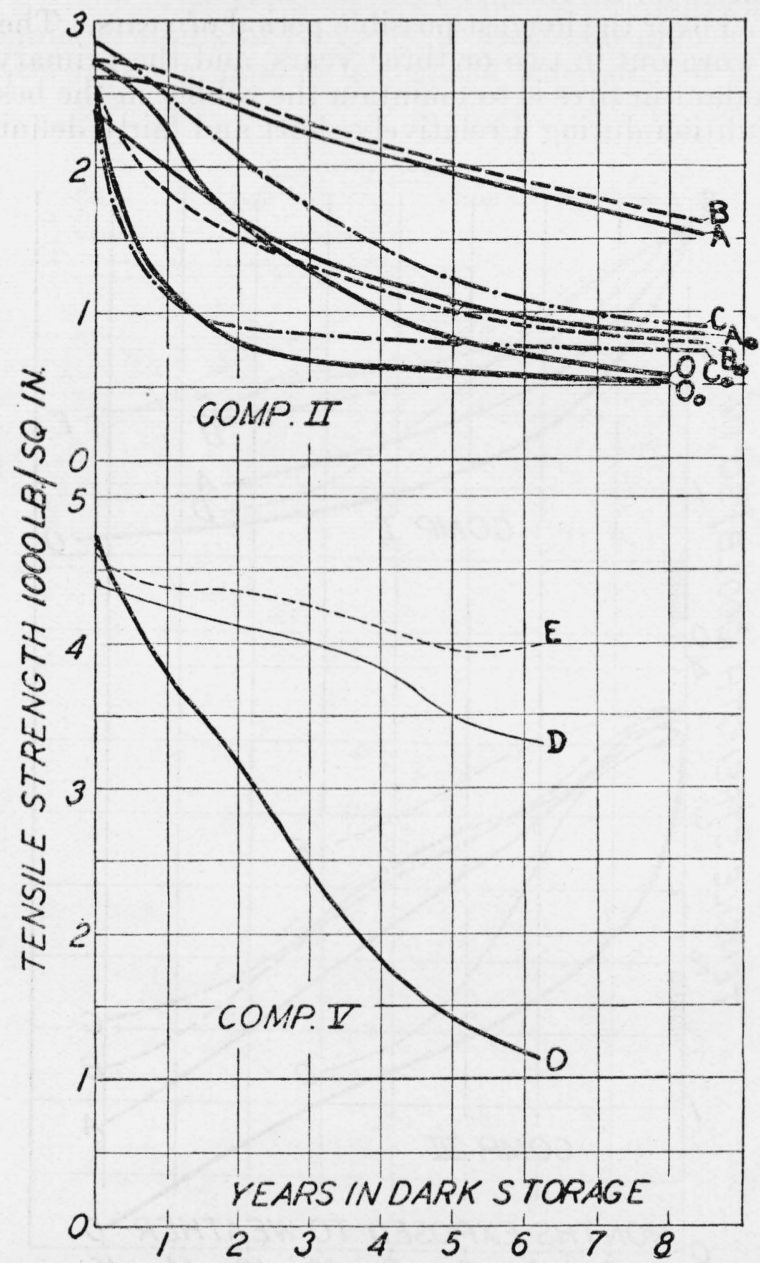

FIGURE 2.-Tensile-strength-time curves for compounds II and $\mathrm{V}$ under dark-storage conditions.

Letter $\mathrm{O}$ indicates base compound (no antioxidant). A, B, C, etc., refer to antioxidants listed in table 1. Subseript 0 indicates an overcured compound.

\section{TENSILE INDEX}

The tensile index is the ratio of the areas under the aging curves of samples made with and without an antioxidant when a definite period of aging is considered. Referring to figure 11 (A), the curve $a b$ represents the aging behavior of rubber containing an antioxidant, and the curve $a c$, the aging of rubber of the same composition containing no antioxidant. The ratio of the area abde to the area acde represents the improvement in tensile strength, during a definite time interval, resulting from the use of the antioxidant. If it is 
assumed that the tensile strength is related to other practically useful properties, such as resistance to abrasion, the tensile index becomes a factor of general importance in evaluating antioxidants. In the case of automobile tires, for example, it is not necessary that the rubber be well preserved over the longest possible period of years. The majority of tires are worn out in two or three years, and the primary function of an antioxidant in tires is to maintain the rubber in the best possible physical condition during a relatively short and fairly definite period.

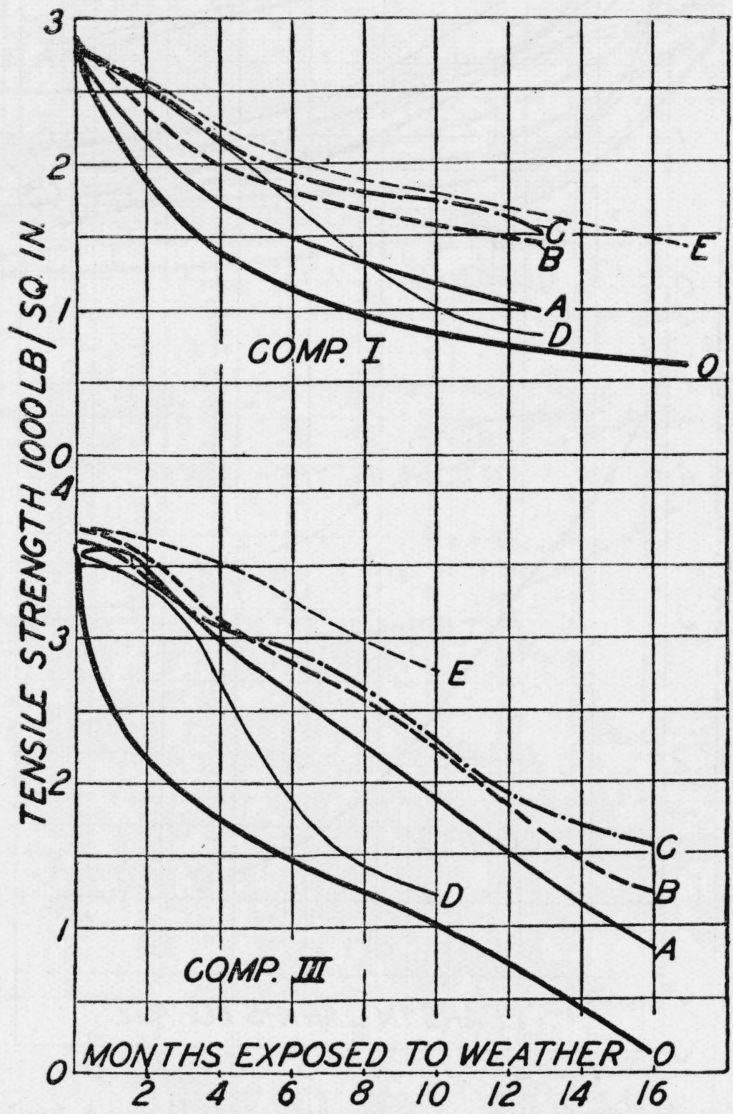

FIGURE 3.-Tensile-strength-time curves for compounds I and III under weather exposure.

Letter $\mathrm{O}$ indicates base compound (no antioxidant). A, B, C, etc., indicate antioxidants listed in table 1.

\section{TIME INDEX}

For certain other types of rubber goods, however, the desideratum is to maintain the rubber in a reasonably good physical condition over the longest possible period of time, and in such cases the time index is the more suitable measure of the efficiency of an antioxidant.

The time index is the ratio of areas between aging curves, and a line representing the minimum useful tensile strength of the rubber. In figure 11 (B), for illustration, $m n$ represents the aging of rubber 
containing an antioxidant, and $m p$ the aging of rubber containing no antioxidant, and the line on arbitrarily represents the tensile strength below which the rubber is no longer useful. The time index is the ratio of the areas mno and mpo.

It may appear that an equally satisfactory result would be obtained by making a_comparison of the times required for the rubber samples

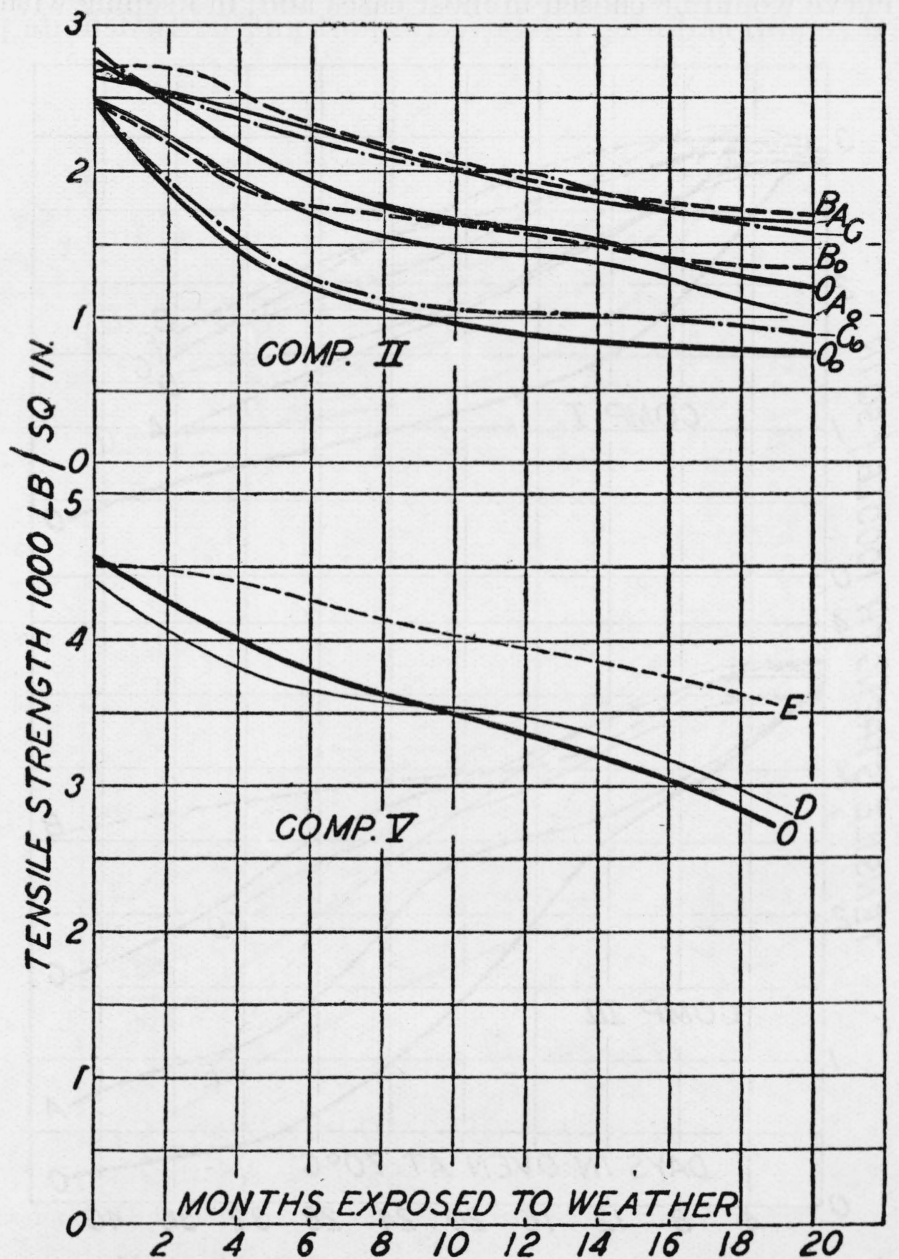

FIGURE 4.-Tensile-strength-time curves for compounds II and $\mathrm{V}$ under weather exposure.

Letter $\mathrm{O}$ indicates base compou nd (no antioxidant). A, B, C, etc., refer to antioxidants listed in table 1. Subscript $\mathrm{o}$ indicates overcured compound.

with and without the antioxidant to reach the limiting useful tensile strength. Such would be the case if the tensile strength of the rubber and other characteristics (as, for instance, resistance to tearing or abrasion) of which it is an index were immaterial so long as the tensile strength exceeded a minimum value. However, an antioxidant which results in a relatively high tensile strength for the rubber throughout 
its life would usually be preferred to one which maintained a low tensile strength even though they should both give the same intercept on the minimum tensile line. This may be illustrated by reference to figure $11(\mathrm{C})$. The curves $x y z$ and $x v z$ represent the aging behavior of rubber containing two different antioxidants and indicate the same span of useful life for the rubber. The antioxidant which gave the former curve would be chosen in most cases and, in keeping with this,

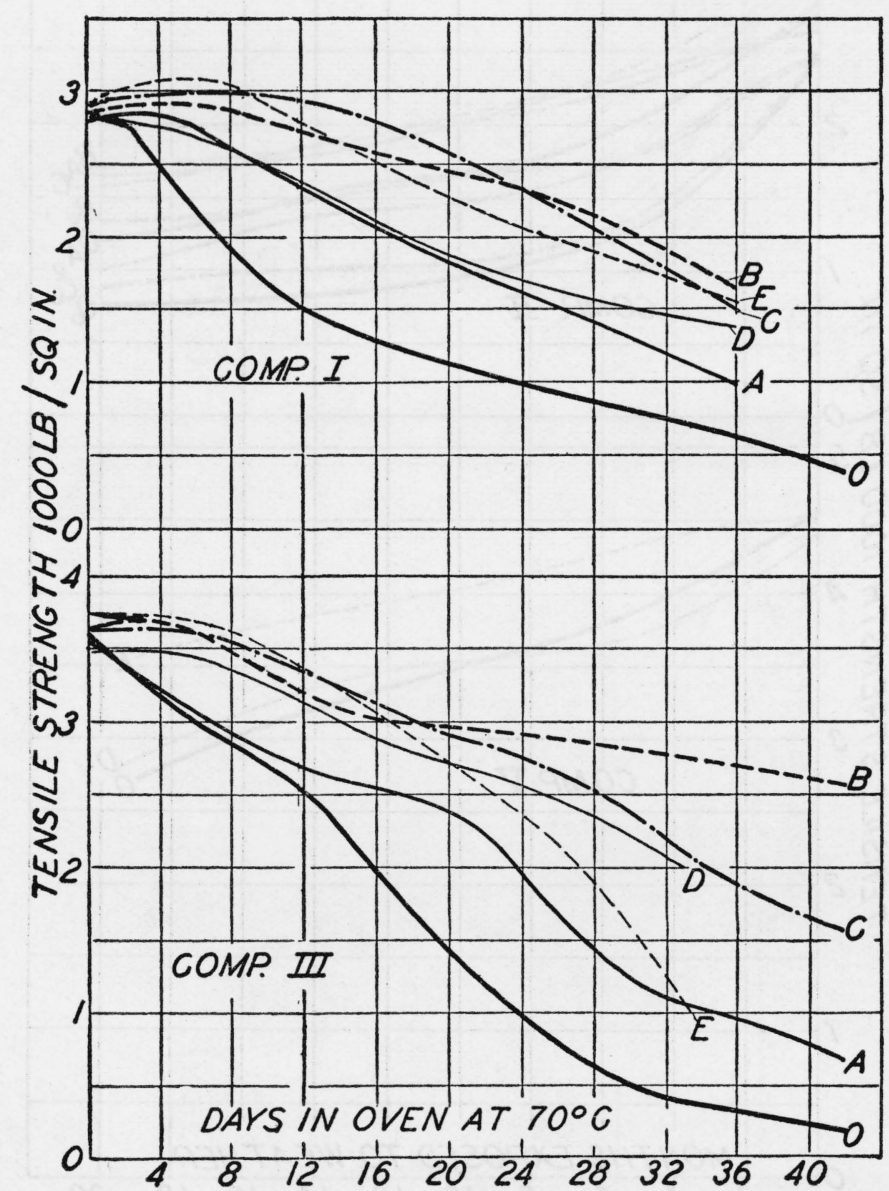

FIGURE 5.-Tensile-strength-time curves for compounds I and III exposed to the $70^{\circ} \mathrm{C}$ oven test.

Letter $\mathrm{O}$ indicates base compound (no antioxidant). A, B, C, etc., refer to antioxidants listed in table 1.

the time index of the former antioxidant would be greater than that of the latter.

\section{COMPUTATION OF TENSILE AND TIME INDEXES}

Tensile and time indexes were determined from the curves shown in the figures, the areas under comparison being measured by plotting on cross-section paper. Tensile indexes were computed for the 
entire period of the test, which, in most cases, was conducted to a point where the sample containing no antioxidant had a relatively low tensile strength. If the designed life of a rubber article were fairly well known, the end-point would be chosen accordingly.

Time indexes were computed on the basis of the time at which the tensile strength of the compound containing an antioxidant reached

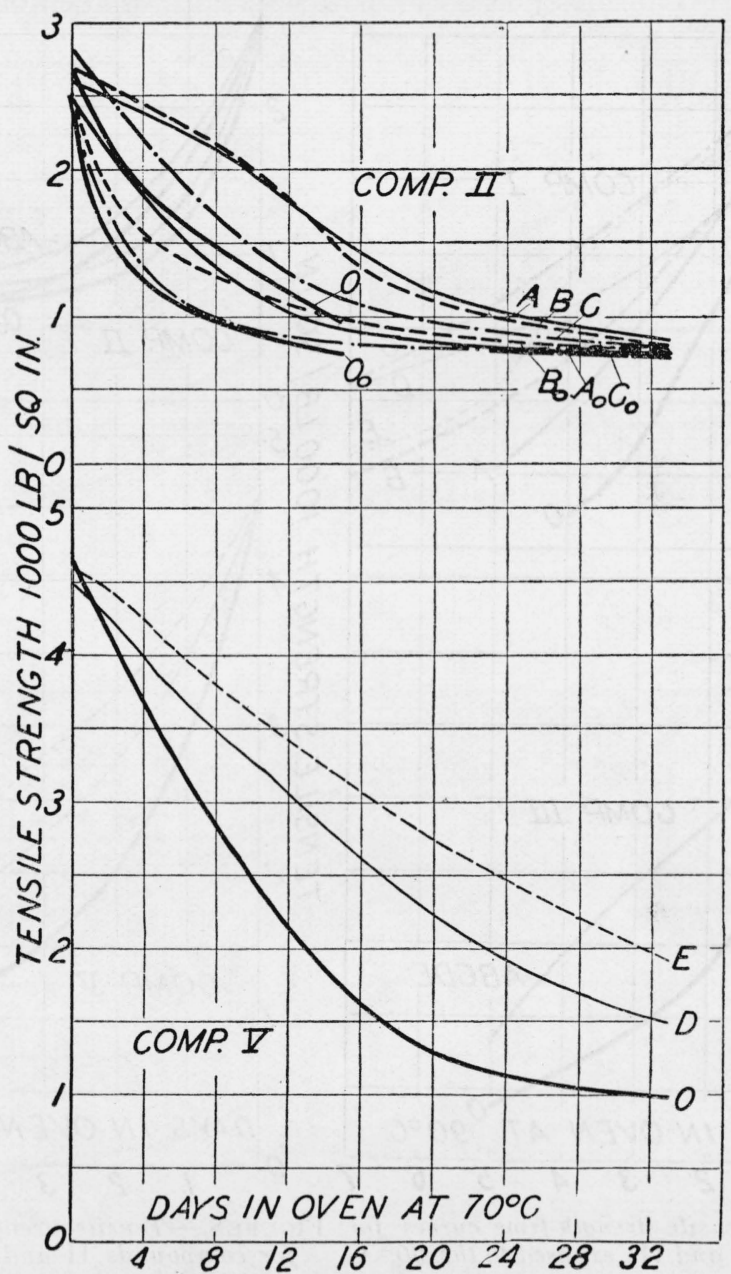

FiguRE 6.-Tensile-strength-time curves for compounds II and $\mathrm{V}$ exposed to the $70^{\circ} \mathrm{C}$ oven test.

Letter $\mathrm{O}$ indicates base compound (no antioxidant). A, B, C, etc., refer to antioxidants listed in table 1. Subscript 0 indicates overcured compound.

a certain lower limit. This lower limit was either $1,500,1,750$, or 2,250 pounds per square inch, depending on the compound under consideration. These figures were selected somewhat arbitrarily and represent approximately one-half of the initial tensile strengths. In computing the time indexes, some of the aging curves were extrapolated for a short distance to bring them to the lower limit. This was 
done, however, only where the trend of the curve was fairly well established and the additional area so added was relatively small.

Since different lower tensile boundaries were used in computing the time indexes in the various tests, the values of the indexes here

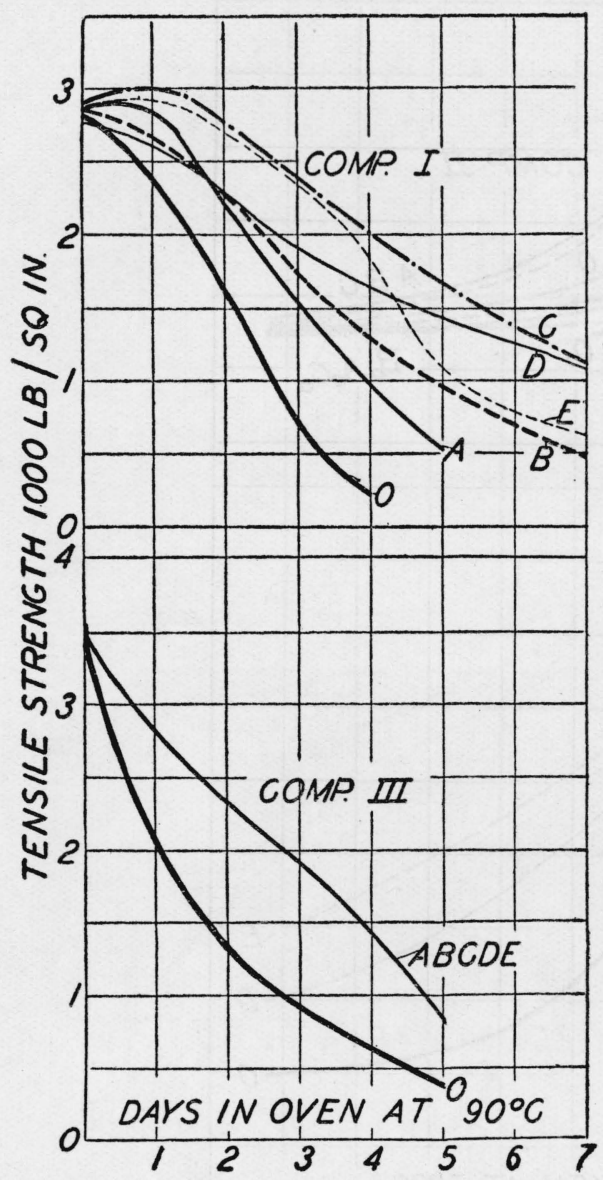
FIGURe 7.-Tensile-strength-time curves for
compounds I and III exposed to the $90^{\circ} \mathrm{C}$ oven test.

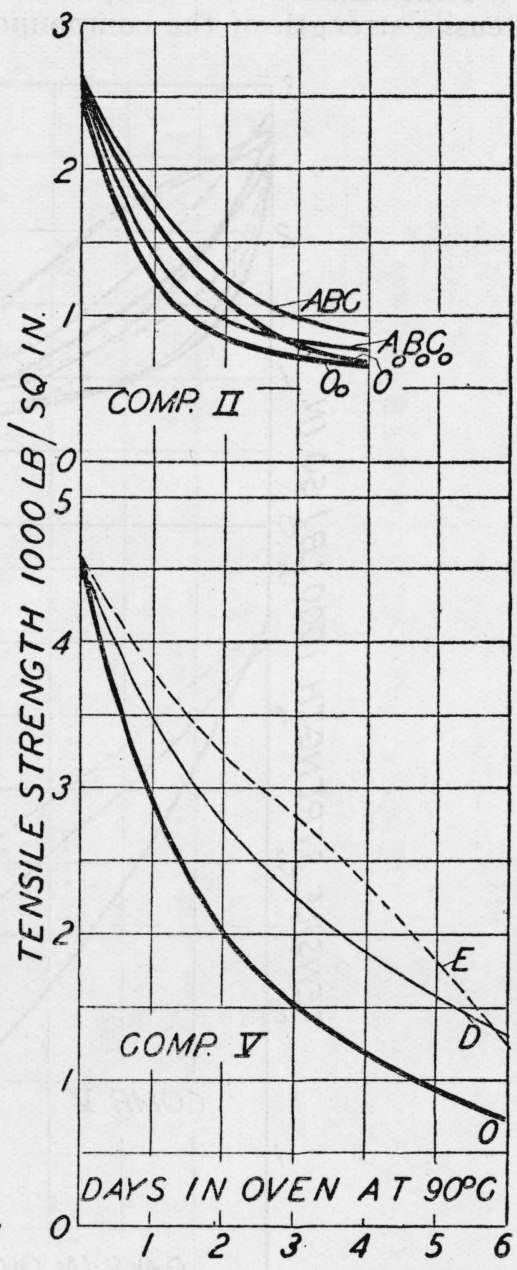

Figure 8.-Tensile-strength-timecurves for compounds II and $\mathrm{V}$ exposed to the $90^{\circ} \mathrm{C}$ oven test.

Letter $\mathrm{O}$ indicates base compound (no antioxidant). A, Letter $\mathrm{O}$ indicates base compound (no antioxi$\mathrm{B}, \mathrm{C}$, etc., refer to antioxidants listed in table 1 .

dant). A, B, C, etc., refer to antioxidants listed in table 1. Subscript o indicates overcured compound.

given are not closely comparable. The logical way to determine the time index would be to conduct aging tests to the point of failure for the compound containing antioxidant as well as the one containing no antioxidant, and to compare the complete curves so obtained. In- 
asmuch as complete curves were not obtained in the present investigation, the computations utilized the available data to the fullest possible extent. This is what is done when a visual comparison is made of incomplete aging curves, and the indexes given are merely ratios designed to give definite expression to comparisons which could otherwise be made only vaguely when many samples are examined.

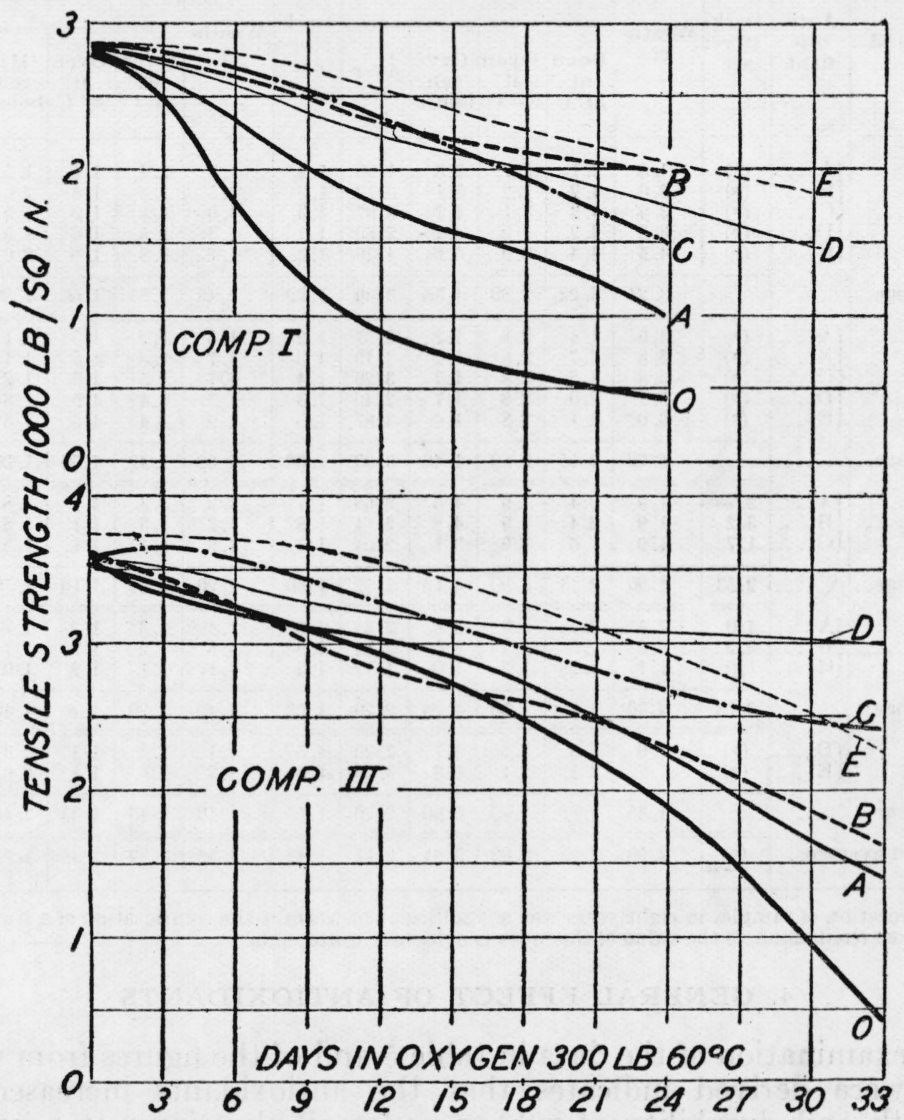

FIGURE 9.-Tensile-strength-time curves for compounds I and III exposed to the oxygen-bomb test.

Letter 0 indicates base compound (no antioxidant). A, B, C, etc., refer to antioxidants listed in table 1.

Any attempt to limit the curves and make strictly logical comparisons of all the aging tests would have the effect of discarding a considerable amount of useful and pertinent information, and would thus decrease the scope and value of the results taken as a whole.

The tensile and time indexes corresponding to the aging curves shown in the figures are listed in table 5. 
TABLE 5.-Time and tensile aging indexes of rubber compounds containing antioxidants

[The composition of the compounds is given in table 2; the names of the antioxidants are shown in table 1. The results for compounds I, III, and V are the average for three cures, except that for compound III with antioxidants A, B, C only the optimum cure was employed; the results for compound II are the average for the undercure and the optimum cure, while those for compound $\mathrm{II}_{0}$ are for the overcure]

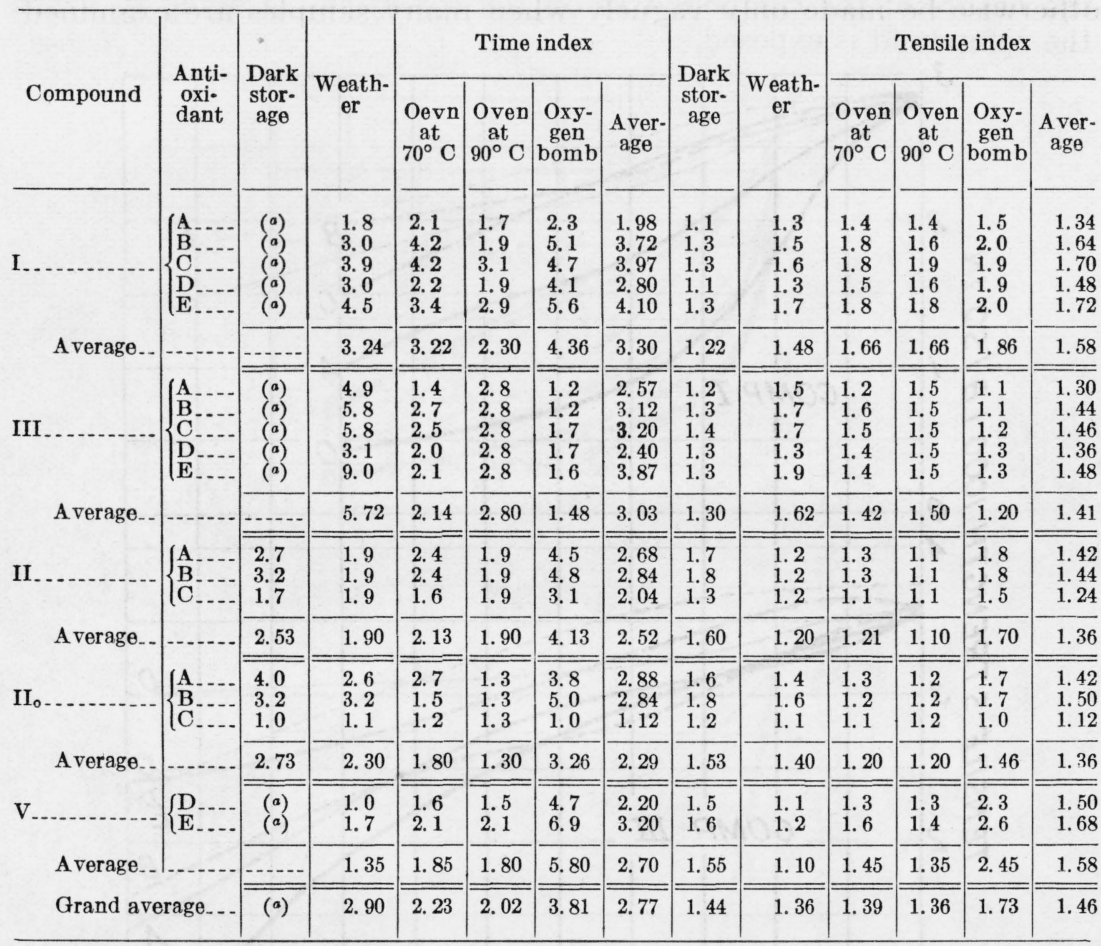

a Deterioration of samples in eight years was not sufficient to warrant the computation of a time index. Under these circumstances the value of the index is evidently quite high.

\section{GENERAL EFFECT OF ANTIOXIDANTS}

An examination of the data in table 5 and of the figures from which they were derived indicates that the antioxidants increased the strength and durability of rubber under all the circumstances that were investigated. The improvement in tensile strength is indicated by a tensile index which is as high as 2 or more in exceptional instances, and averages 1.46 for all tests included in the investigation. The increase in the life of the rubber, as measured by the time index, was too high to be determined in the case of compounds I, III, and V when stored in the dark. It amounted to as much as 5 or 6 under several conditions, and averages 2.77 for the numerical values that were recorded.

\section{BEHAVIOR OF ANTIOXIDANTS IN DIFFERENT COMPOUNDS}

An inspection of the average indexes indicates that the antioxidants are somewhat more effective in compounds I, III, and V than in compound II, though under some conditions some of the antioxidants are quite effective in compound II. In the case of the rubber- 
sulphur compound IV, the measurements are not shown. All the antioxidants were effective in increasing the durability, but they were not a cure-all for the mediocre aging properties which characterize rubber-sulphur compounds under most circumstances. Taken as a whole, the effectiveness of antioxidants depends not so much on the nature of the compound as on the conditions of aging to which the compound is exposed.

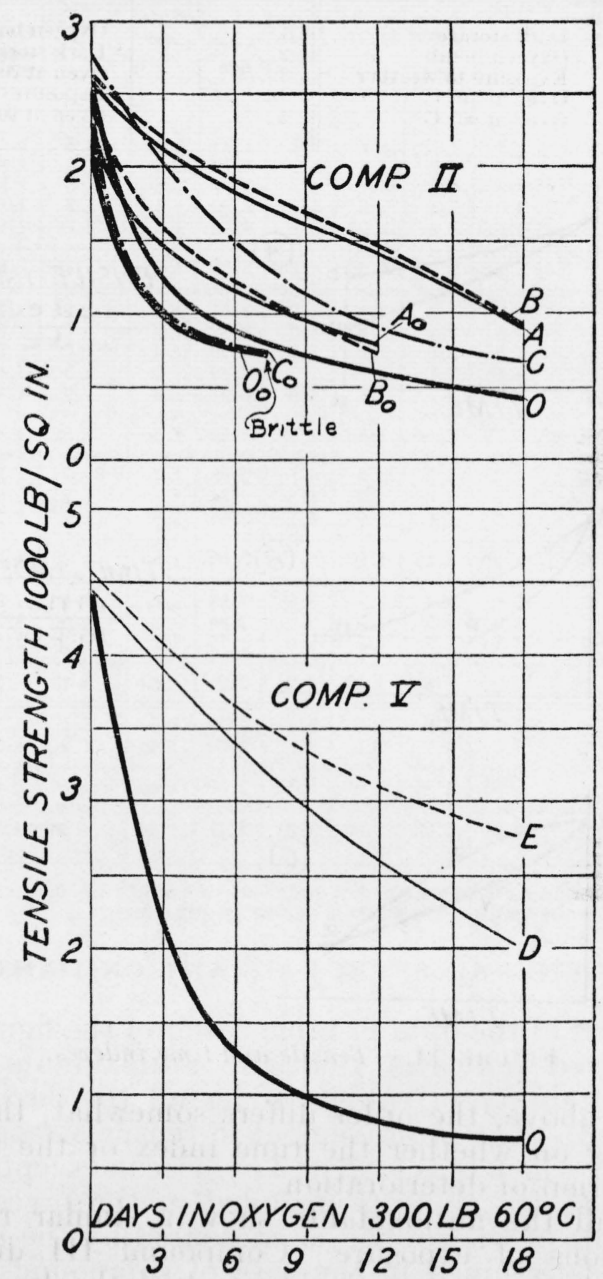

FiguRE 10.-Tensile-strength-time curves for compounds II and $\mathrm{V}$ exposed to the oxygen-bomb test.

Letter $\mathrm{O}$ indicates base compound (no antioxidant). A, B, C, etc., refer to antioxidants listed in table 1. Subscript 0 indicates overcured compound.

\section{BEHAVIOR OF ANTIOXIDANTS UNDER DIFFERENT CONDITIONS OF EXPOSURE}

An examination of the data in table 5 also indicates that the conditions under which the rubber samples were exposed caused the largest variations in the indexes. If average values of indexes for all com- 
pounds are considered, the effectiveness of antioxidants may be ascertained for the different conditions of exposure. These are arranged in the order of their decreasing effectiveness (antioxidants were most effective under condition 1 , and least effective under condition 5) as follows:

\begin{tabular}{|c|c|c|c|}
\hline Condition & Time index & Condition & Tensile index \\
\hline $\begin{array}{l}1 \\
2 \\
3 \\
4 \\
5\end{array}$ & $\begin{array}{l}\text { Dark storage } \\
\text { Oxygen bomb } \\
\text { Exposure to weather } \\
\text { Oven at } 70^{\circ} \mathrm{C} \\
\text { Oven at } 90^{\circ} \mathrm{C}\end{array}$ & $\begin{array}{l}1 \\
2 \\
3 \\
4 \\
5\end{array}$ & $\begin{array}{l}\text { Oxygen bomb } \\
\text { Dark storage } \\
\text { Oven at } 70^{\circ} \mathrm{C} \\
\text { Exposure to weather, or } \\
\text { Oven at } 90^{\circ} \mathrm{C}\end{array}$ \\
\hline
\end{tabular}
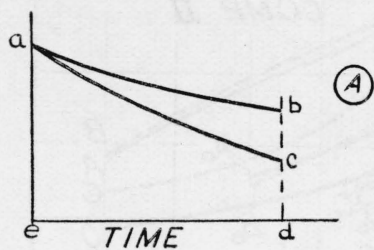

TENSILE INDEX

$\frac{a b d e}{a c d e}$

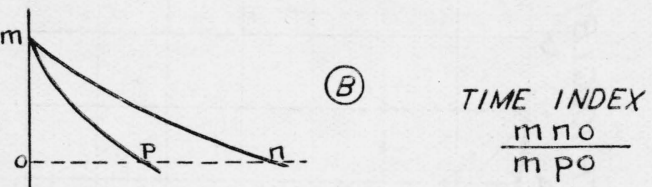

TIME

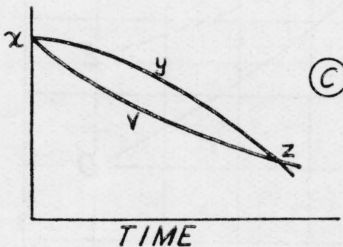

(C)

Figure 11.-Tensile and time indexes.

As indicated above, the order differs somewhat, though not radically, depending on whether the time index or the tensile index is taken as a criterion of deterioration.

In general, all the antioxidants show a similar response to the various conditions of exposure. Compound III differs from the other compounds, in that antioxidants had the least effect during aging in the oxygen bomb and the most effect during weather exposure. In the weather-exposure tests, the greater effect in compound III, which is transparent, and in compound I, which is light in color, can be explained by the darkening effect of the antioxidants. (Compounds II, $\mathrm{II}_{\mathrm{o}}$, and $\mathrm{V}$ were initially dark in color.) Reference to table 1 shows that the protection afforded by antioxidants under weather exposure is in accord with the darkening produced by them, which indicates that light was the chief deteriorating agent. 
The relatively high degree of protection which antioxidants afford against deterioration in the oxygen bomb, in most cases, is an indication that their primary function, in keeping with their name, is that of negative catalysts of oxidation. Only in the case of compound III do the antioxidants fail to bring about a very considerable improvement when aging is conducted in the oxygen bomb. An examination of the results reveals no explanation for this behavior.

The results obtained under different conditions of exposure have a direct bearing on the matter of accelerated-aging tests. Consider, for example, the testing of a rubber product for use where exposure to weather is the chief deteriorating factor. If the average indexes for each compound are classified with reference to the acceleratedaging test, which most nearly corresponds to weather exposure, the tabulation shown in table 6 results.

TABLE 6.-Most suitable accelerated test for weather exposure, based on time and tensile indexes

\begin{tabular}{|c|c|c|}
\hline Compound & Time index & Tensile index \\
\hline 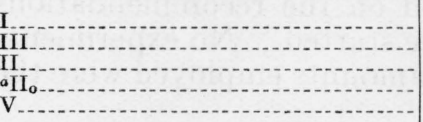 & $\begin{array}{l}\text { Oven at } 70^{\circ} \mathrm{C} \\
\text { Oven at } 90^{\circ} \mathrm{C} \\
\text { Oven at } 90^{\circ} \mathrm{C} \\
\text { Oven at } 70^{\circ} \mathrm{C} \\
\text { Oven at } 90^{\circ} \mathrm{C}\end{array}$ & $\begin{array}{l}\text { Oven at } 70^{\circ} \text { or } 90^{\circ} \mathrm{C} \text {. } \\
\text { Oven at } 90^{\circ} \mathrm{C} . \\
\text { Oven at } 70^{\circ} \mathrm{C} . \\
\text { Oxygen bomb. } \\
\text { Oven at } 90^{\circ} \mathrm{C} \text {. }\end{array}$ \\
\hline
\end{tabular}

a Overcure of II.

This tabulation points to the oven test at $90^{\circ} \mathrm{C}$, a test not commonly employed, as being the one of those tried which was most nearly comparable to weather exposure. The oxygen-bomb test, in most cases, would indicate a relatively greater durability than would be found for rubber exposed to weather.

If a rubber product is to be used where conditions similar to those encountered in dark storage are the chief deteriorating factors, accelerated-aging tests which would show the best correspondence are given in table 7 .

TABLE 7.-Most suitable accelerated test for dark-storage conditions based on time and tensile indexes

\begin{tabular}{|c|c|c|}
\hline Compound & Time index & Tensile index \\
\hline 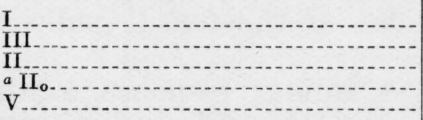 & $\begin{array}{l}\text { Oxygen bomb } \\
\text { Oven at } 90^{\circ} \mathrm{C}- \\
\text { Oven at } 70^{\circ} \mathrm{C} \\
\text { Oxygen bomb }\end{array}$ & $\begin{array}{l}\text { Oven at } 70 \text { or } 90^{\circ} \mathrm{C} \text {. } \\
\text { Oxygen bomb. } \\
\text { Do. } \\
\text { Do. } \\
\text { Oven at } 70^{\circ} \mathrm{C} .\end{array}$ \\
\hline
\end{tabular}

a Overcure of compound II.

This tabulation points to the oxygen bomb as being the most suitable test in the majority of cases, while one of the oven tests is indicated for the other cases.

\section{RELATIVE VALUE OF ANTIOXIDANTS}

The several antioxidants differ considerably in protective action, but the variations are not sufficiently systematic or uniform to admit of arranging them in any general order of efficiency. Furthermore, the data are not complete in this respect, because all five antioxidants 
were used simultaneously in only two compounds. Inasmuch as the results obtained in the case of these two compounds were not consistent, they do not warrant the placing of any general rating on the five antioxidants.

Antioxidants A, B, and C were used comparably in three compounds, I, II, and III, as were also antioxidants D and E, in compounds, I, III, and V. In compounds I and III, the antioxidants, arranged in order of decreasing protective action, were C, B, A, but in compound II the order was B, A, C, or A, B, C. In the general average $\mathrm{B}$ and $\mathrm{C}$ are close together, while $\mathrm{A}$ is somewhat lower, but the variability of the results with different compounds is such that the results are not highly significant.

A comparison of antioxidants $\mathrm{D}$ and $\mathrm{E}$ leads to more consistent results. Only in one test did antioxidant $\mathrm{D}$ show a higher protective value than did $\mathrm{E}$. The numerical results, however, show no consistent ratio between the two antioxidants.

In making comparisons between compounds containing different antioxidants, consideration should be given to the relative amounts of each antioxidant used. As stated previously, the proportions employed in the present work were based on the recommendations of the manufacturers at the time tests were started. No experiments were conducted to determine whether the amounts employed were the most effective or the most economical.

\section{SUMMARY}

1. All antioxidants increased the useful life of rubber compounds under practically all of the conditions of test.

2. The effectiveness of the antioxidants varied between wide limits, depending upon the conditions of exposure, the type of compound, and the particular antioxidant used.

3. Two means for expressing the effectiveness of an antioxidant numerically are suggested, a time index, which is a measure of the increase in time during which a rubber compound will remain serviceable, and a tensile index, which is a measure of the improvement in average tensile strength. A comparison of the indexes obtained by different accelerated-aging tests with those obtained under some conditions of natural aging, affords a means for choosing an aging test best suited to a particular rubber product.

Washington, March 26, 1935. 